\title{
Synthesis and Characterization of Functionalized Magnetic Nanoparticles for the Detection of Pesticide
}

\author{
Shu Taira, ${ }^{1}$ Daisaku Kaneko, ${ }^{1}$ Kazuki Onuma, ${ }^{2}$ Akio Miyazato, ${ }^{1}$ Tomoyuki Hiroki, ${ }^{2}$ \\ Yasuko Kawamura-Konishi, ${ }^{3}$ and Yuko Ichiyanagi ${ }^{2}$ \\ ${ }^{1}$ School of Material Science, Japan Advanced Institute of Science and Technology, 1-1 Asahidai, Nomi City, Ishikawa 923-1292, Japan \\ ${ }^{2}$ Department of Physics, Graduate School of Engineering, Yokohama National University, 79-5 Tokiwadai, Hodogaya-ku, \\ Yokohama 240-8501, Japan \\ ${ }^{3}$ Department of Food Science, Faculty of Bioresources and Environmental Sciences, Ishikawa Prefectural University, 1-308 Suematsu, \\ Nonoichi, Ishikawa 921-8836, Japan \\ Correspondence should be addressed to Shu Taira, s-taira@jaist.ac.jp
}

Received 13 February 2012; Accepted 9 April 2012

Academic Editor: Liane M. Rossi

Copyright () 2012 Shu Taira et al. This is an open access article distributed under the Creative Commons Attribution License, which permits unrestricted use, distribution, and reproduction in any medium, provided the original work is properly cited.

\begin{abstract}
We synthesized magnetic nanoparticles (MNPs) by mixing aqueous solutions of $3 d$ transition metal chlorides $\left(\mathrm{MCl}_{2} \cdot n \mathrm{H}_{2} \mathrm{O}\right)$ and a sodium metasilicate nonahydrate $\left(\mathrm{Na}_{2} \mathrm{SiO}_{3} \cdot 9 \mathrm{H}_{2} \mathrm{O}\right)$ in order to produce monodispersed MNPs in a single step. The particle size can be controlled by adjusting the annealing temperature. We characterized the MNPs by X-ray diffraction (XRD), superconducting quantum interference device (SQUID), transmission electron microscopy (TEM), Fourier transform infrared (FT-IR), and zetapotential measurement. Paramagnetic and superparamagnetic behaviors were found for the obtained samples depending on the particle size $(d=3.0-4.6 \mathrm{~nm})$. The synthesized MNPs could be modified with the amino-, phenyl-, and carboxy- groups on MNPs' surface by silanization procedure, respectively. The purpose of functionalizing the surface of the nanoscale magnetic particles was to realize subsequent capture and detection with desired other molecules by nanoparticle assisted laser ionization/desorption mass spectrometry.
\end{abstract}

\section{Introduction}

Nanoscale magnetic particles have attracted much attention because they are able to be transported to targeted locations [1-4] by means of an external magnetic field as well as to be used for data storage [5] and magnetic resonance imaging $[6,7]$.

Synthesis methods of magnetic nanoparticles (MNPs) have been developed for composing various kinds of MNPs and controlling the sizes in the range of $1-100 \mathrm{~nm}$ [810]. Coprecipitation method is the most convenient way to synthesize MNPs from metal chloride solution (i.e., iron, manganese, nickel, etc.) by the addition of base solution. MNPs are precipitated under optimum temperature, $\mathrm{pH}$, and ionic strength [11-13] due to solubility change.

Nanometer-scale spheres show very interesting characteristic phenomena such as quantum size effect or magnetic quantum tunneling and have intrinsic instability over longer haul for the morphology. To stabilize MNP character, chemical coating on naked MNP surface was developed [1416]. For example, MNP with 10-20 nm can be stabilized in 2-aminoethanethiol $(0.5 \mathrm{M})$ [14]. Polymer or surfactant coating is also used to protect the MNP configuration and avoid aggregation [17-21]. These techniques can be applied to protection of MNP morphology although we should pay attention to synthesis conditions under the complicated method.

We have developed a method for synthesizing MNPs by mixing aqueous solutions of $3 d$ transition metal chlorides $\left(\mathrm{MCL}_{2} \cdot n \mathrm{H}_{2} \mathrm{O}\right)$ and a sodium metasilicate nonahydrate $\left(\mathrm{Na}_{2} \mathrm{SiO}_{3} \cdot 9 \mathrm{H}_{2} \mathrm{O}\right)$ to obtain monodispersed and bite-sized MNPs in a single step. The particle size depended on the annealing temperature and time $[11,12]$. MNPs prepared by this method were surrounded by amorphous $\mathrm{SiO}_{2}$, so we can prevent them from aggregation and degradation. Besides, Si ions are located on the surface, therefore, the 
optional functional group can be modified on MNP surface by silanization procedure [2]. Modification and coating on MNP surface does not only perform to protect MNP morphology but also serve to use functionalization with objective components, such as drug [22], enzyme [23], and amino acid [24]. It is possible that various functional groups are modified (i.e., phenyl [25], thiol [24], fluorine, chlorine, etc.) on the MNP by the silanization method.

In this research, we functionalized MNPs by the (3aminopropyl)triethoxysilane ( $\gamma$-APTES), phenyltriethoxysilane (PTES) or triethoxysilylpropyl succinic anhydride (TESPSA) to modify with amino- [2], phenyl- [26], and carboxy- [27] groups on the MNP's surface. Moreover, MNPs can be applied to analytical field. From recent advances in mass spectrometry, it is well known that nanoparticles with metal oxide cores can ionize the molecule for the laser desorption/ionization (LDI) of analytes in mass spectrometry (MS) [28]. Functionalized MNPs also serve as an ionization-assisting material in nanoparticle-assisted laser desorption/ionization (nano-PALDI) MS, which gives no background peaks. Therefore, Nano-PALDI MS can be used in analysis of various compounds such as metabolite, drug, and oligonucleotide [29-31]. Especially, phenyl groupmodified (Ph-) MNPs have demonstrated the capture and ionization of target analyte by chemointeraction [26]. In this context, we investigated Ph-MNPs for the ability of recovery and detection of pesticide as a novel application for agricultural science.

\section{Material and Methods}

2.1. Synthesis and Characterization of Magnetic Nanoparticles with Precipitation of Wet Process Method. We developed simple preparation method of MNP. The $\gamma$ - $\mathrm{Fe}_{2} \mathrm{O}_{3}$ MNPs surrounded by amorphous $\mathrm{SiO}_{2}\left(\mathrm{a}-\mathrm{SiO}_{2}\right)$ were prepared by mixing aqueous solutions of $\mathrm{FeCl}_{2} \cdot 4 \mathrm{H}_{2} \mathrm{O}$ (WAKO Pure Chemicals Japan) and $\mathrm{Na}_{2} \mathrm{SiO}_{3} \cdot 9 \mathrm{H}_{2} \mathrm{O}$ (JUNSEI Chemical Japan). $\mathrm{FeCl}_{2} \cdot 4 \mathrm{H}_{2} \mathrm{O}(10 \mathrm{mM})$ and $\mathrm{Na}_{2} \mathrm{SiO}_{3} \cdot 9 \mathrm{H}_{2} \mathrm{O}(10 \mathrm{mM})$ were each dissolved in $500 \mathrm{~mL}$ of distilled water, and the two solutions were mixed. After 10 minutes of stirring, the resulting precipitates were washed several times with distilled water and dried at $353 \mathrm{~K}$ in a water bath. The dried samples were crushed in a porcelain mortar and then annealed in air for 6 hours at $873 \mathrm{~K}$ or $973 \mathrm{~K}$ in a furnace.

\subsection{Functionalization of MNPs by Silanization Method.} In this time, we prepared three types of functionalized MNPs with (i) amino, (ii) phenyl or, (iii) carboxy groups (Figure 1(a)). For each functionalization, the (3aminopropyl)triethoxysilane ( $\gamma$-APTES), phenyltriethoxysilane (PTES) or triethoxysilylpropyl succinic anhydride (TESPSA) solution was added to the solid $\gamma$ - $\mathrm{Fe}_{2} \mathrm{O}_{3} \mathrm{MNPs}$, respectively. The reaction mixture was stirred at $298 \mathrm{~K}$ for 10 minutes and then heated to 403 or $298 \mathrm{~K}$. Three or six hours after the mixture was cooled to room temperature, it was washed three times with ultrapure water $(\geq 18.2 \Omega$, Milli-Q SP, Millipore Co.) and ethanol, then dried at $350 \mathrm{~K}$.
Fourier transform infrared (FT-IR) spectra were observed to confirm the modification of functional groups, respectively, even after washing the samples several times to remove physisorbed organic molecules. Zeta potential was also measured using a Zetasizer Nano ZS (Malvern, UK) for recognition. Before and after the modification, each sample was examined by $\mathrm{CuK} \alpha \mathrm{X}$-ray powder diffraction (XRD) $(\lambda=0.154 \mathrm{~nm})$. DC magnetization was measured using a superconducting quantum interference device (SQUID) magnetometer (Quantum Design, MPMS) under a \pm 40 $\mathrm{kOe}$ magnetic field; the magnetization measurements were performed at temperatures ranging from 5 to $300 \mathrm{~K}$. The morphology of the MNPs was investigated by transmission electron microscopy (TEM; H-7100, Hitachi, Japan).

\subsection{Capture and Analysis of Pesticide Samples by Phenyl} Group-Modified MNPs. In the capture and analysis experiments, pyriminobac methyl (Methyl 2-(4,6-dimethoxy-2pyrimidinyloxy)-6-(1-methoxyiminoethyl) benzoate; $M w$ : 361.3) that is chemical herbicides of pesticide was used as aromatic samples (Figure 1(b)). The Phenyl group-modified (Ph-) MNPs (1 mg) were suspended in $150 \mu \mathrm{L}$ of $70 \%$ methanol containing $10 \mathrm{ppm}$ of pyriminobac methyl, and this suspension was stirred for $5 \mathrm{~min}$. After recovery of the Ph-MNP's suspension by an external magnetic force of permanent magnet, the supernatant was discarded. The precipitate particles were resuspended in $1 \mathrm{~mL}$ of $70 \%$ methanol as a washing procedure, and this suspension was stirred for $1 \mathrm{~min}$. The Ph-MNP's precipitation was again recovered by external magnetic force, and the supernatant was discarded. The Ph-MNPs suspension was evaluated by MS to confirm the existence of the target pesticide on the Ph-MNP through $\pi-\pi$ interaction. The $1 \mu \mathrm{L}$ of suspension of sample and $\mathrm{Ph}-\mathrm{MNPs}$ were dropped on target plates with a pipette.

The usefulness of the MNPs for their trapping ability and as an ionization-assisting material in MS was confirmed by a matrix-assisted laser desorption/ionization (MALDI) time of flight (TOF) instrument (Voyager-DE-RP; Applied Biosystems, Germany) equipped with a nitrogen laser emitting at $337 \mathrm{~nm}$. The analyte surface was irradiated with 100 laser shots in the positive ion detection mode. As a control, the same procedure was conducted using the original unfunctionalized MNPs.

\section{Results}

3.1. Physical Characterization of Original Nanoparticles. The XRD pattern of the iron-based MNP indicated the spinel $\gamma-\mathrm{Fe}_{2} \mathrm{O}_{3}$ structure. The broad peaks at $2 \theta=35$ and 60 degrees were confirmed to be the (311) reflection and the (440) reflection of $\gamma-\mathrm{Fe}_{2} \mathrm{O}_{3}$. The peak below $2 \theta=30$ degrees was determined to have originated from amorphous $\mathrm{SiO}_{2}$ (Figure 2(a)) [10].

FT-IR analysis exhibited the presence of Si-O (1100$\left.900 \mathrm{~cm}^{-1}\right)$ and $\mathrm{O}-\mathrm{H}\left(3400-3100 \mathrm{~cm}^{-1}\right)$ bonding as chemical bonds on the surface of the MNPs (Figure 2(b)). 


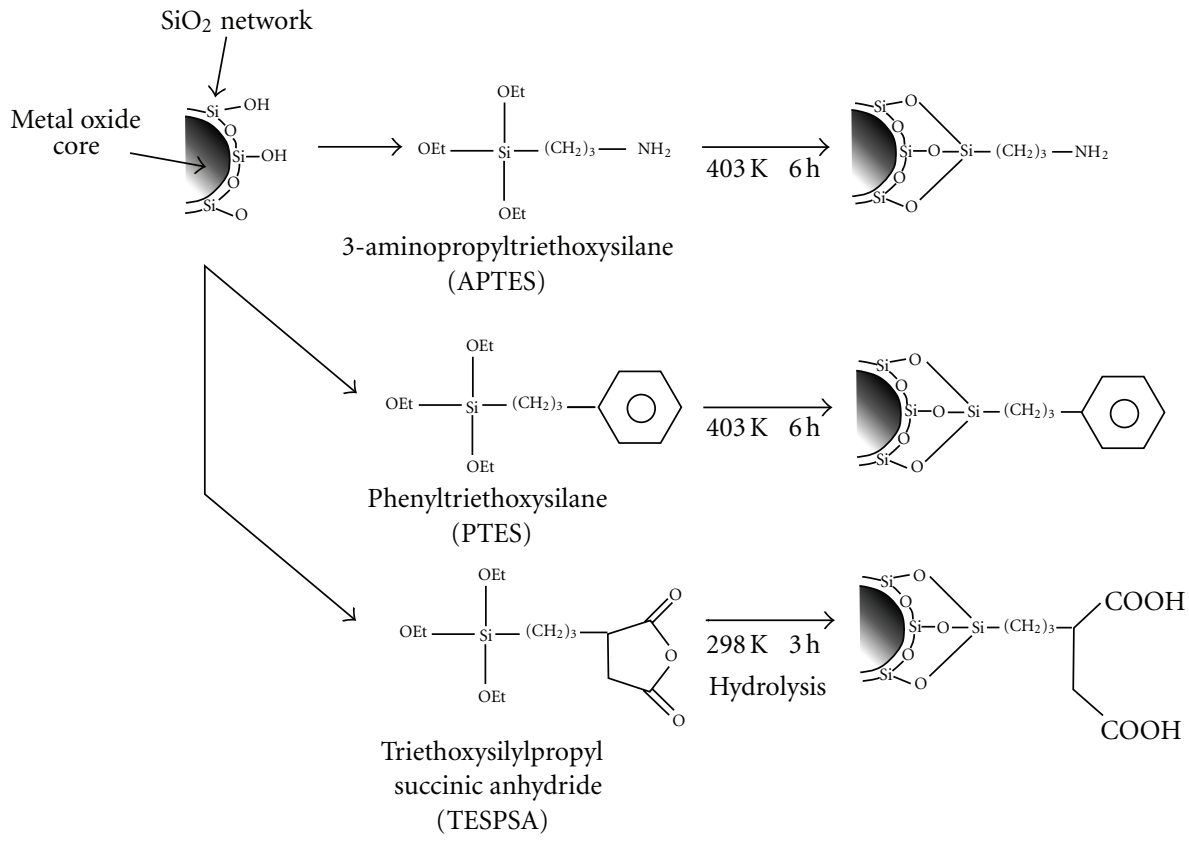

(a)

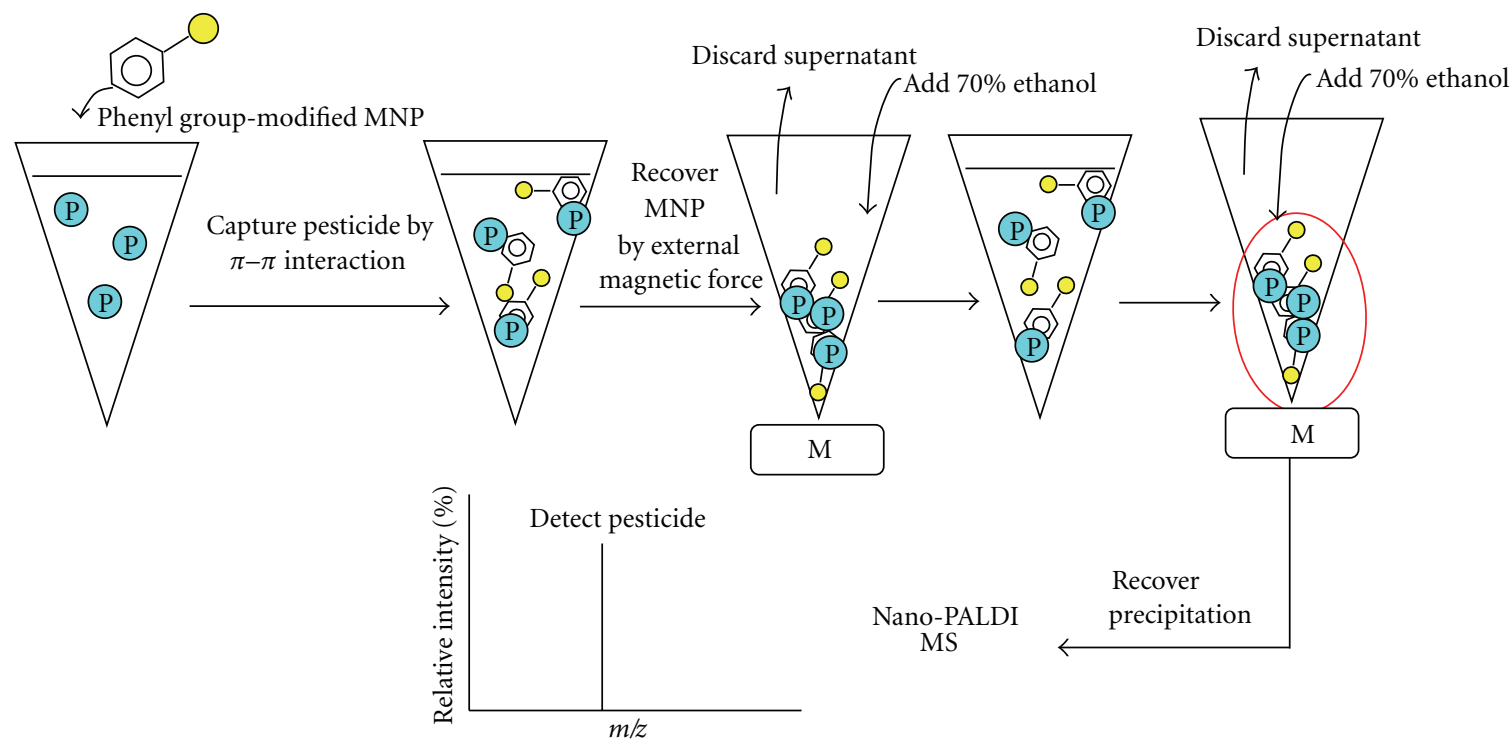

(P) Pesticide

M Permanent magnet

(b)

FIGURE 1: Schematic illustration of functionalization of magnetic nanoparticle by silanization procedure (a) and the capture and ionization of target pesticide by phenyl group-modified magnetic nanoparticle (b).

The results of magnetization indicated different property by annealing temperature. In the case of the annealing temperature at $873 \mathrm{~K}$, the magnetization of the iron-based MNPs increased linearly with increasing magnetic field; that is, the particle showed paramagnetism at $300 \mathrm{~K}$ (Figure 2(c)). In the case of the annealing temperature at $973 \mathrm{~K}$, superparamagnetic behavior was shown with sigmoid curve at $300 \mathrm{~K}$ (Figure 2(d)). These MNPs precipitates could be easily attracted from water solution by means of an external magnetic field.

TEM images of the MNPs were shown (Figures 2(e) and 2(f)). Obtained images exhibited that the MNPs did not aggregate but disperse. The iron-based nanoparticles which were annealed at $873 \mathrm{~K}$ showed small groups for both the primary particle diameters $(3.0 \pm 0.6 \mathrm{~nm})$ (mean \pm SEM; $\left.n=10^{2}\right)$ (Figure $\left.2(\mathrm{e})\right)$. The diameter of the iron-based 


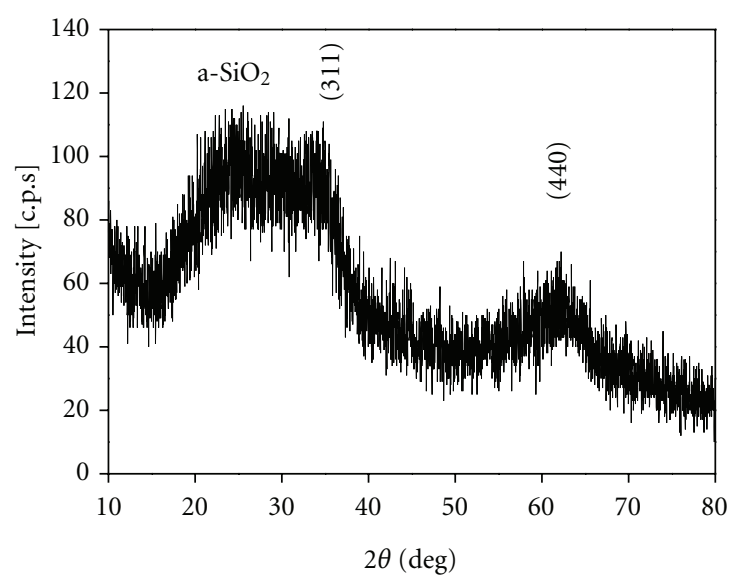

(a)

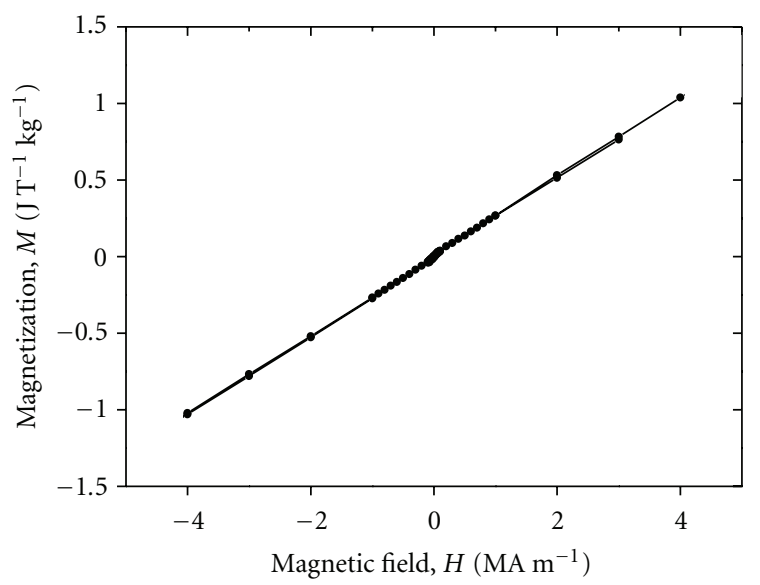

(c)

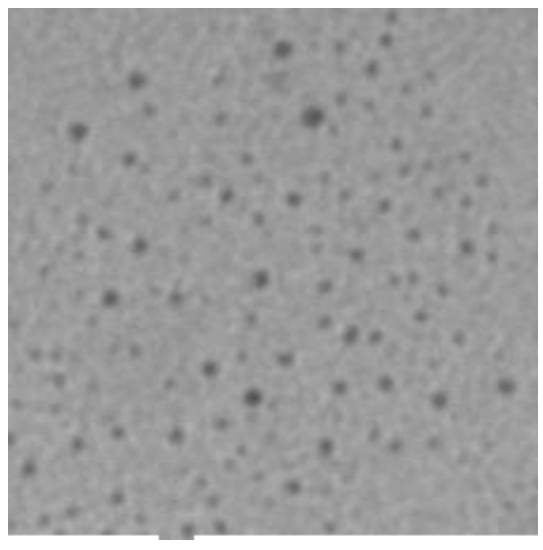

(e)

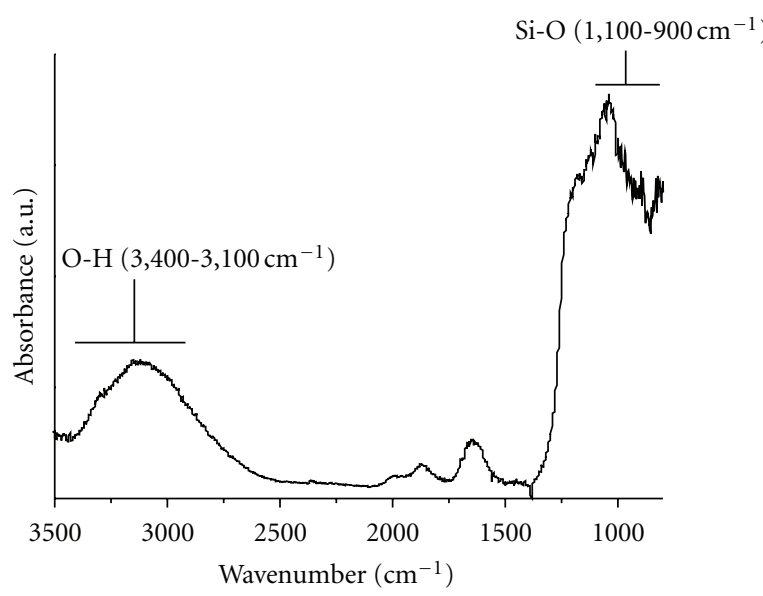

(b)

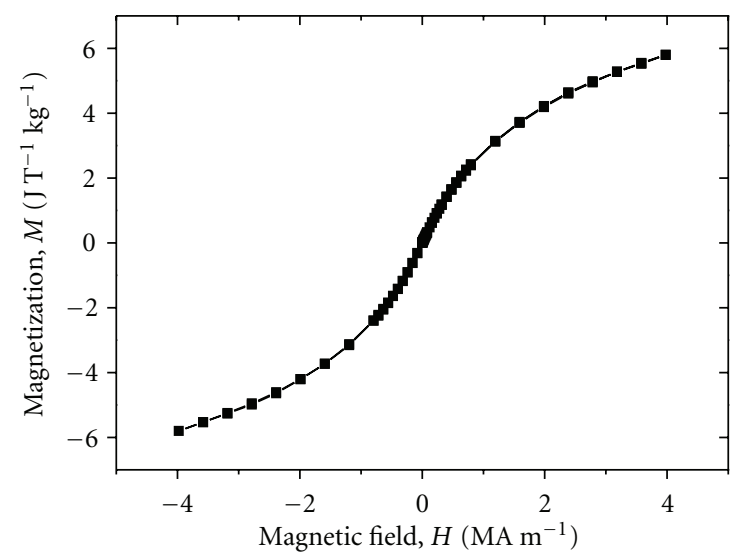

(d)

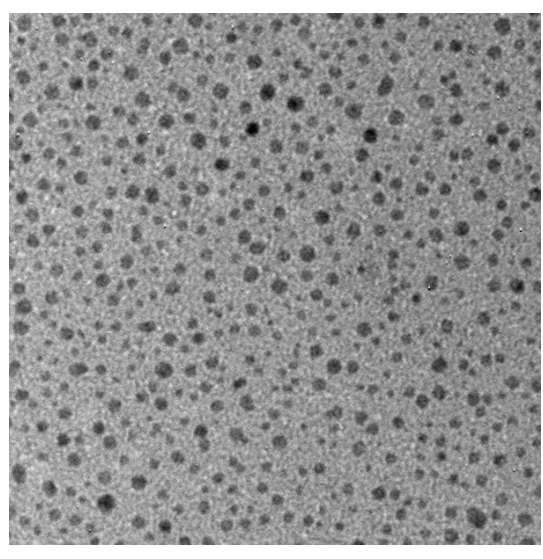

$40 \mathrm{~nm}$

(f)

Figure 2: The CuK $\alpha$ X-ray powder diffraction pattern (a), FT-IR spectrum, $M-H$ curves for annealing temperature at $873 \mathrm{~K}$ (c) or $973 \mathrm{~K}$ (d), and TEM images of original magnetic nanoparticle for annealing temperature at $873 \mathrm{~K}$ (e) or $973 \mathrm{~K}$ (f), respectively.

nanoparticles which were annealed at $973 \mathrm{~K}$ was measured to be $4.5 \pm 0.9 \mathrm{~nm}$ (mean $\pm \mathrm{SEM} ; n=10^{2}$ ) (Figure 2(f)). A significant difference was observed between these two iron-based MNPs $(P<0.05$ with unpaired $t$-test), indicating that the particle sizes were controlled through the annealing temperatures. Interestingly, the annealing temperature affected magnetization property. The property of paramagnetism changed to superparamagnetism, which indicated that magnetism value increased 6 times. 


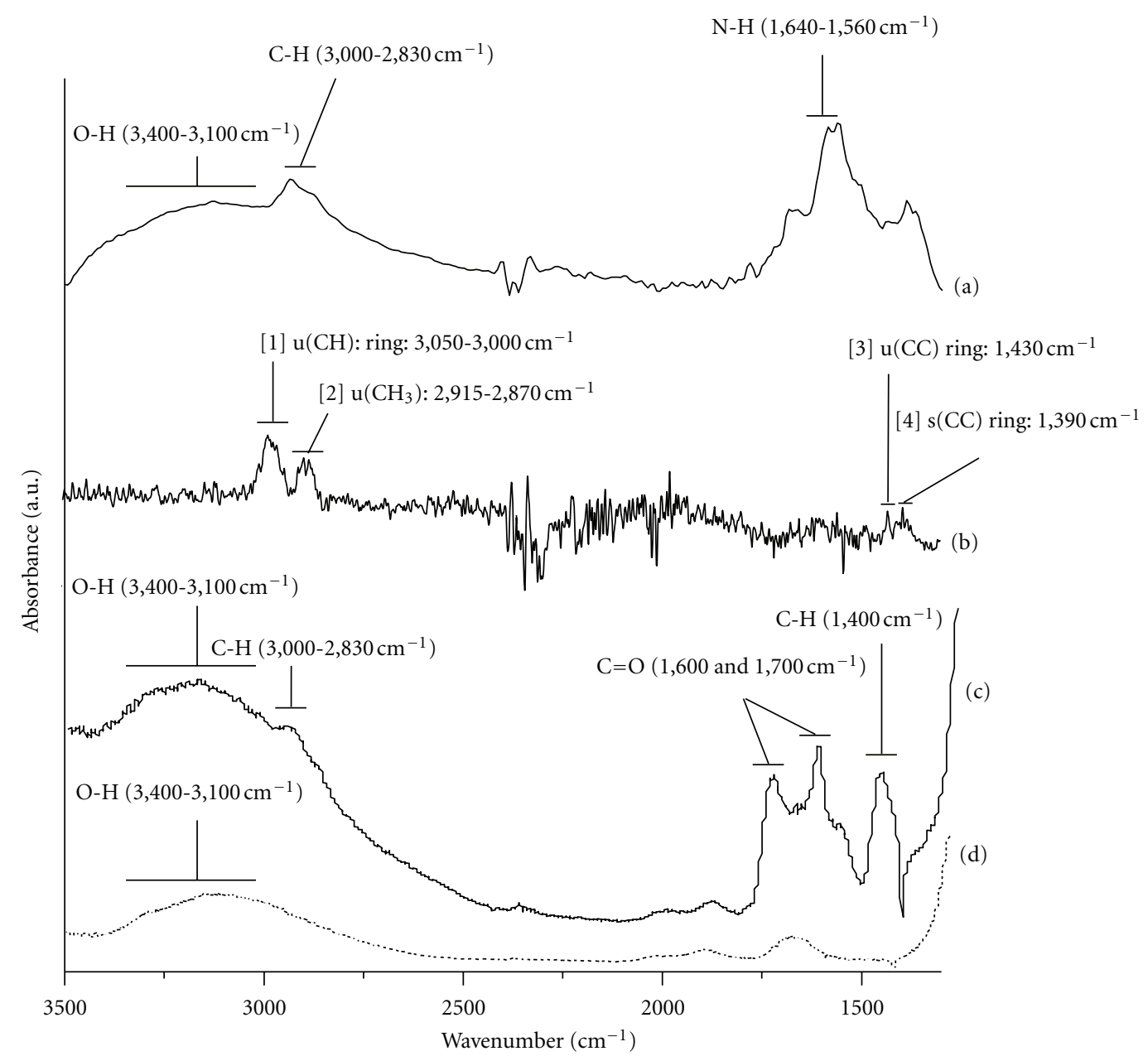

FIgURE 3: FT-IR spectra of amino- (a), phenyl- (b), carboxy-group modified (c), and original (d) magnetic nanoparticles, respectively.

3.2. Physical Characterization of Functionalized MNP. The modification of basic functional group such as amino, phenyl and carboxy groups is important because these groups can be used to bind various reagents by covalent bond or chemical interaction. FT-IR spectra indicated the existence of these functional groups on MNP, respectively. For the amino groups on the MNP, the presence of $\mathrm{N}-\mathrm{H}(1,640-$ $\left.1,540 \mathrm{~cm}^{-1}\right)$, C-H $\left(3,000-2,830 \mathrm{~cm}^{-1}\right)$ and $\mathrm{O}-\mathrm{H}(3,400-$ $3,100 \mathrm{~cm}^{-1}$ ) bonding as chemical bonds on the surface of the MNPs was confirmed (Figure 3(a)). In the case of phenylgroup modified MNPs, the corresponding signal for the aromatic ring of PTES was observed for the $\mathrm{C}-\mathrm{C}$ ring $(1,430$ and $\left.1,390 \mathrm{~cm}^{-1}\right), \mathrm{CH}_{3}$ stretch $\left(2,915-2,870 \mathrm{~cm}^{-1}\right)$ and the C$\mathrm{H}$ ring stretch $\left(3,050-3,000 \mathrm{~cm}^{-1}\right)$ on the MNP surface, even after multiple washings of the samples in order to remove excess organic molecules. The broad peak of $\mathrm{O}-\mathrm{H}(3,400-$ $3,100 \mathrm{~cm}^{-1}$ ) bonding was disappeared due to modification of PTES (Figure $3(\mathrm{~b})$ ). For carboxy groups, typical $\mathrm{C}=\mathrm{O}$ peaks $\left(1,600\right.$ and $\left.1,700 \mathrm{~cm}^{-1}\right), \mathrm{C}-\mathrm{H}$ peaks $(3,000-2,830$ and $\left.1,400 \mathrm{~cm}^{-1}\right)$ and $\mathrm{O}-\mathrm{H}\left(3,400-3,100 \mathrm{~cm}^{-1}\right)$ were detected for the first time in the spectrum of the functionalized particles, respectively (Figure $3(\mathrm{c})$ ), whereas only the $\mathrm{O}-\mathrm{H}$ $\left(3,400-3,100 \mathrm{~cm}^{-1}\right)$ peak was observed in the spectrum of the original MNPs (Figure 3(d)). An Si-O (1,100-900 $\mathrm{cm}^{-1}$ ) peak still remained from all functionalized MNPs.

The zeta-potentials of the nanoparticles were measured by a Zetasizer using the laser Doppler velocimetry technique. For amino group-modified MNP, an isoelectric point was found for $\sim \mathrm{pH} 9.8$ (Inverted black triangle points in Figure 4). The nanoparticles showed positive charge in $<\mathrm{pH}$ 10. This indicated that $\mathrm{NH}_{2}$ groups on nanoparticle's surface transformed into $\mathrm{NH}_{3}{ }^{+}$group. The zeta potential was more than $+30 \mathrm{mV}$ that was considered as the threshold value for electrostatic stabilization [32].

In the case of phenyl group-modified MNPs (Ph-MNPs) (White triangle points in Figure 4), the MNPs showed negative charges at $\mathrm{pH}$ 3.0-11.0. The zeta potential of the Ph-MNPs was less negative than that of the original MNPs (White circle points in Figure 4), which indicated that the phenyl groups decreased the effect of the $\mathrm{OH}$ group on the MNP surface. Black square points in Figure 4 showed a plot of the zeta potential of the carboxyl groups modified MNP. From this measurement, negative charges on the surface were confirmed. It appears that carboxyl groups maintain the equilibrium position between $\mathrm{COOH}$ and $\mathrm{COO}^{-}+\mathrm{H}^{+}$in solution, and the equilibrium shifts to the right at higher $\mathrm{pH}$ 


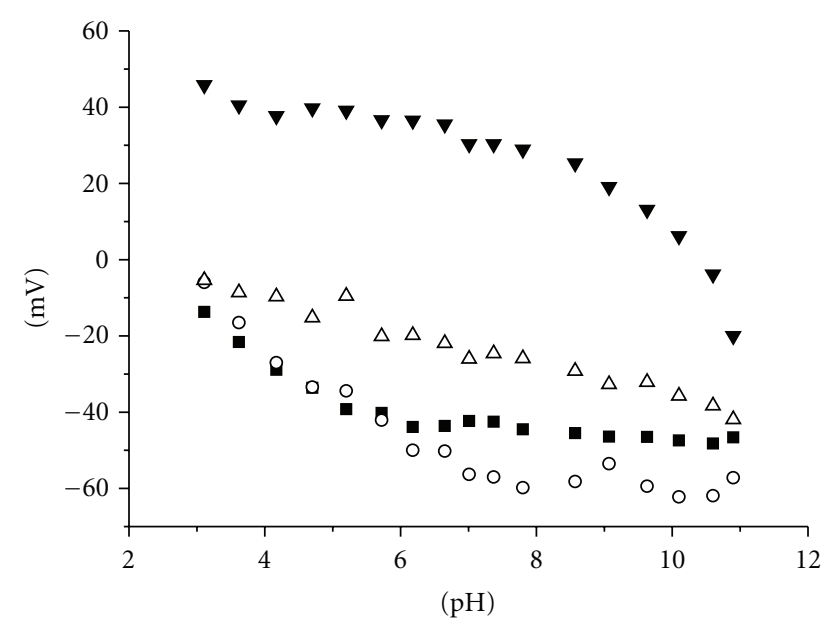

Figure 4: Zeta potential of amino- $(\boldsymbol{\nabla})$, phenyl- $(\triangle)$, original $(\boldsymbol{\square})$, and carboxy-group modified (०) magnetic nanoparticles, respectively.
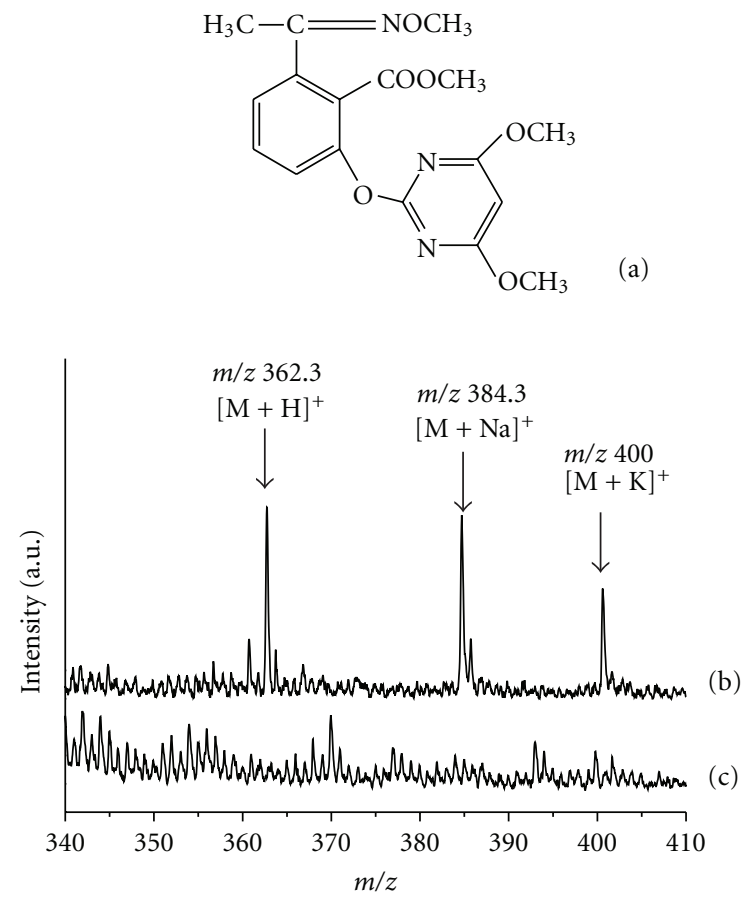

Figure 5: Chemical structure of pyriminobac methyl as pesticide (a), nano-PALDI mass spectra of pyriminobac methyl with phenyl group-modified magnetic nanoparticle (b), or original magnetic nanoparticle (c).

values. These functionalized particles tend to show a negative potential as the $\mathrm{pH}$ value increases. Thus the modification with functional groups on magnetic nanoparticles was succesful. The amino- or carboxyl-modified functionalized nanoparticles can electrostatically or covalently conjugate to other molecules such as drugs and biomolecules and they improve hydrophilic properties of the nanoparticles. As a result, biocompatibility is expected.
For the phenyl group-modified MNP (Ph-MNP), we could capture the desired molecule chemical interaction. In the previous report, we have successfully achieved selective trapping and detection of aromatic molecules by $\pi-\pi$ interaction [26]. In this time, we investigated whether the pyriminobac methyl as (Figure 5(a)) pesticide is captured and detected by $\mathrm{Ph}-\mathrm{MNP}$. We could successfully recover Ph-MNP by an external magnetic force. After a washing procedure, protonated $(\mathrm{m} / \mathrm{z} 362.3)$, sodium adducted $(\mathrm{m} / \mathrm{z} 384.3)$, and potassium adducted $(\mathrm{m} / \mathrm{z} 400.0)$ form of pyriminobac methyl were detected, respectively (Figure $5(\mathrm{~b})$ ). On the contrast, in the case of the original MNP, no signal was observed (Figure 5(c)). The main body of pyriminobac methyl constitutes aromatic structure. Thus, this result indicated that this Ph-MNP possesses the ability of pesticide capturing after washing due to $\pi-\pi$ interaction between phenyl groups on MNP's surface and pesticide.

\section{Conclusion}

$\gamma$ - $\mathrm{Fe}_{2} \mathrm{O}_{3}$ MNPs surrounded by amorphous $\mathrm{SiO}_{2}$ were prepared by the wet chemical method. The obtained MNP's magnetization property and diameter were increased with increasing annealing temperature. Functionalization of MNP by the silanization method could provide amino, phenyl and carboxy group-modified MNPs. Functional phenyl groupmodified MNP could capture aromatic molecule such as one of pesticides and could be employed in investigation of pesticide residue from agricultural products and land in the next work.

\section{Acknowledgments}

The authors thank Professor M. Takagi, Professor K. Ebitani, and Professor Y. Takamura, for providing technical assistance and advice. This research was supported by a WAKATE-B grant from the Japan Society for the Promotion of Science to S. Taira, a Grant-in-Aid to S. Taira from Kinki Innovation Center Japan and from Mitani Foundation for R\&D.

\section{References}

[1] S. Moritake, S. Taira, Y. Sugiura, M. Setou, and Y. Ichiyanagi, "Magnetic nanoparticle-based mass spectrometry for the detection of biomolecules in cultured cells," Journal of Nanoscience and Nanotechnology, vol. 9, no. 1, pp. 169-176, 2009.

[2] S. Moritake, S. Taira, Y. Ichiyanagi et al., "Functionalized nano-magnetic particles for an in vivo delivery system," Journal of Nanoscience and Nanotechnology, vol. 7, no. 3, pp. 937-944, 2007.

[3] S. Taira, Y. Z. Du, Y. Hiratsuka, T. Q. P. Uyeda, N. Yumoto, and M. Kodaka, "Loading and unloading of molecular cargo by DNA-conjugated microtubule," Biotechnology and Bioengineering, vol. 99, no. 3, pp. 734-739, 2008.

[4] C. Chen, J. Geng, F. Pu, X. Yang, J. Ren, and X. Qu, "Polyvalent nucleic acid/mesoporous silica nanoparticle conjugates: dual stimuli-responsive vehicles for intracellular drug delivery," Angewandte Chemie, vol. 50, no. 4, pp. 882-886, 2011. 
[5] A. Zentko, V. Kavečanský, M. Mihalik et al., "Magnetic relaxation and memory effect in nickel-chromium cyanide nanoparticles," Acta Physica Polonica A, vol. 113, no. 1, pp. 511-514, 2008.

[6] T. Skajaa, D. P. Cormode, P. A. Jarzyna et al., "The biological properties of iron oxide core high-density lipoprotein in experimental atherosclerosis," Biomaterials, vol. 32, no. 1, pp. 206-213, 2011.

[7] Y. M. Huh, Y. W. Jun, H. T. Song et al., "In vivo magnetic resonance detection of cancer by using multifunctional magnetic nanocrystals," Journal of the American Chemical Society, vol. 127, no. 35, pp. 12387-12391, 2005.

[8] Z. Wang, P. Xiao, B. Shen, and N. He, "Synthesis of palladiumcoated magnetic nanoparticle and its application in Heck reaction," Colloids and Surfaces A, vol. 276, no. 1-3, pp. 116121, 2006.

[9] Y. Ichiyanagi and Y. Kimishima, "Structural, magnetic and thermal characterizations of $\mathrm{Fe} 2 \mathrm{O} 3$ nanoparticle systems," Journal of Thermal Analysis and Calorimetry, vol. 69, no. 3, pp. 919-923, 2002.

[10] Y. Ichiyanagi and Y. Kimishima, "Magnetic and structural studies of $\mathrm{Ni}(\mathrm{OH})_{2}$ monolayered nanoclusters," Japanese Journal of Applied Physics, Part 1, vol. 35, no. 4, pp. 2140-2144, 1996.

[11] Y. Ichiyanagi, T. Uehashi, and S. Yamada, "Magnetic properties of Ni-Zn ferrite nanoparticles," physica Status Solidi C, vol. 12, pp. 3485-3488, 2004.

[12] Y. Ichiyanagi, H. Kondoh, T. Yokoyama, K. Okamoto, K. Nagai, and T. Ohta, "X-ray absorption fine-structure study on the $\mathrm{Ni}(\mathrm{OH}) 2$ monolayer nanoclusters," Chemical Physics Letters, vol. 379, no. 3-4, pp. 345-350, 2003.

[13] I. Robinson, L. D. Tung, S. Maenosono, C. Wälti, and N. T. K. Thanh, "Synthesis of core-shell gold coated magnetic nanoparticles and their interaction with thiolated DNA," Nanoscale, vol. 2, no. 12, pp. 2624-2630, 2010.

[14] Y. Tanaka and S. Maenosono, "Amine-terminated waterdispersible FePt nanoparticles," Journal of Magnetism and Magnetic Materials, vol. 320, no. 19, pp. L121-L124, 2008.

[15] A. H. Latham and M. E. Williams, "Versatile routes toward functional, water-soluble nanoparticles via trifluoroethylesterPEG-thiol ligands," Langmuir, vol. 22, no. 9, pp. 4319-4326, 2006.

[16] H. G. Bagaria, E. T. Ada, M. Shamsuzzoha, D. E. Nikles, and D. T. Johnson, "Understanding mercapto ligand exchange on the surface of FePt nanoparticles," Langmuir, vol. 22, no. 18, pp. 7732-7737, 2006.

[17] P. C. Scholten and J. A. P. Felius, "The magnetical and rheological behavior of aggregating magnetic suspensions," Journal of Magnetism and Magnetic Materials, vol. 85, no. 13, pp. 107-113, 1990.

[18] M. De Cuyper and M. Joniau, "Mechanistic aspects of the adsorption of phospholipids onto lauric acid stabilized Fe3O4 nanocolloids," Langmuir, vol. 7, no. 4, pp. 647-652, 1991.

[19] A. Wooding, M. Kilner, and D. B. Lambrick, "“Stripped" magnetic particles. Applications of the double surfactant layer principle in the preparation of water-based magnetic fluids," Journal of Colloid And Interface Science, vol. 149, no. 1, pp. 98104, 1992.

[20] E. E. Carpenter, C. T. Seip, and C. J. O’Connor, "Magnetism of nanophase metal and metal alloy particles formed in ordered phases," Journal of Applied Physics, vol. 85, no. 8, pp. 51845186, 1999.

[21] M. H. Sousa, F. A. Tourinho, J. Depeyrot, G. J. Da Silva, and M. C. F. L. Lara, "New electric double-layered magnetic fluids based on copper, nickel, and zinc ferrite nanostructures," Journal of Physical Chemistry B, vol. 105, no. 6, pp. 1168-1175, 2001.

[22] S. Santra, C. Kaittanis, J. Grimm, and J. M. Perez, "Drug/dyeloaded, multifunctional iron oxide nanoparticles for combined targeted cancer therapy and dual optical/magnetic resonance imaging," Small, vol. 5, no. 16, pp. 1862-1868, 2009.

[23] P. A. Johnson, H. J. Park, and A. J. Driscoll, "Enzyme nanoparticle fabrication: magnetic nanoparticle synthesis and enzyme immobilization," Methods in Molecular Biology, vol. 679, pp. 183-191, 2011.

[24] S. Moritake, S. Taira, T. Hatanaka, M. Setou, and Y. Ichiyanagi, "Preparation of amino acid conjugated nano-magnetic particles for delivery systems," e-Journal of Surface Science and Nanotechnology, vol. 5, pp. 60-66, 2007.

[25] S. Taira, Y. Sahashi, S. Shimma, T. Hiroki, and Y. Ichiyanagi, "Nanotrap and mass analysis of aromatic molecules by phenyl group-modified nanoparticle," Analytical Chemistry, vol. 83, no. 4, pp. 1370-1374, 2011.

[26] S. Taira, Y. Sahashi, S. Shimma, T. Hiroki, and Y. Ichiyanagi, "Nanotrap and mass analysis of aromatic molecules by phenyl group-modified nanoparticle," Analytical Chemistry, vol. 83, no. 4, pp. 1370-1374, 2011.

[27] T. Hiroki, S. Taira, H. Katayanagi et al., "Functional magnetic nanoparticles for use in a drug delivery system," Journal of Physics, vol. 200, no. 12, Article ID 122003, 2010.

[28] K. Tanaka, Y. Ido, S. Akita, Y. Yoshida, and T. Yoshida, "Detection of high mass molecules by laser desorption timeof-flight mass spectrometry," in Proceedings of the 2nd JapanChina Joint Symposium on Mass Spectrometry, p. 185, 1987.

[29] S. Taira, K. Kitajima, H. Katayanagi, E. Ichiishi, and Y. Ichiyanagi, "Manganese oxide nanoparticle-assisted laser desorption/ionization mass spectrometry for medical applications," Science and Technology of Advanced Materials, vol. 10, no. 3, Article ID 034602, 2009.

[30] S. Taira, Y. Sugiura, S. Moritake, S. Shimma, Y. Ichiyanagi, and M. Setou, "Nanoparticle-assisted laser desorption/ionization based mass imaging with cellular resolution," Analytical Chemistry, vol. 80, no. 12, pp. 4761-4766, 2008.

[31] S. Taira, I. Osaka, S. Shimma et al., "Oligonucleotide analysis by nanoparticle-assisted laser desorption/ionization mass spectrometry," Analyst, vol. 137, no. 9, pp. 2006-2010, 2012.

[32] D. Cunningham, R. E. Littleford, W. E. Smith et al., "Practical control of SERRS enhancement," Faraday Discussions, vol. 132, pp. 135-145, 2006. 


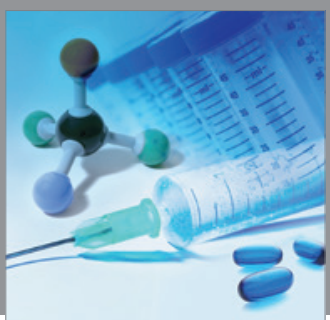

International Journal of

Medicinal Chemistry

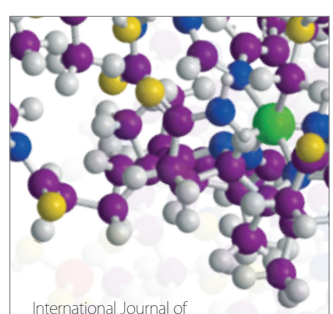

Carbohydrate Chemistry

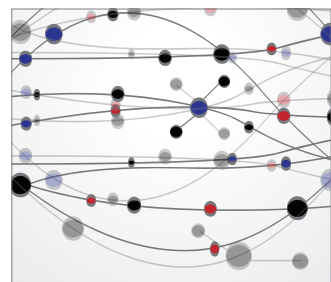

The Scientific World Journal
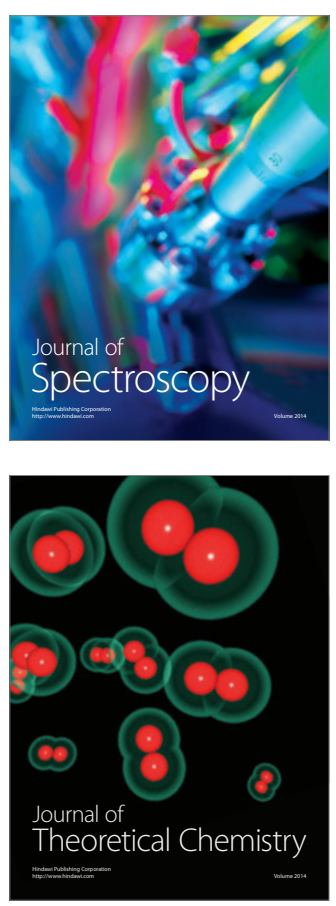
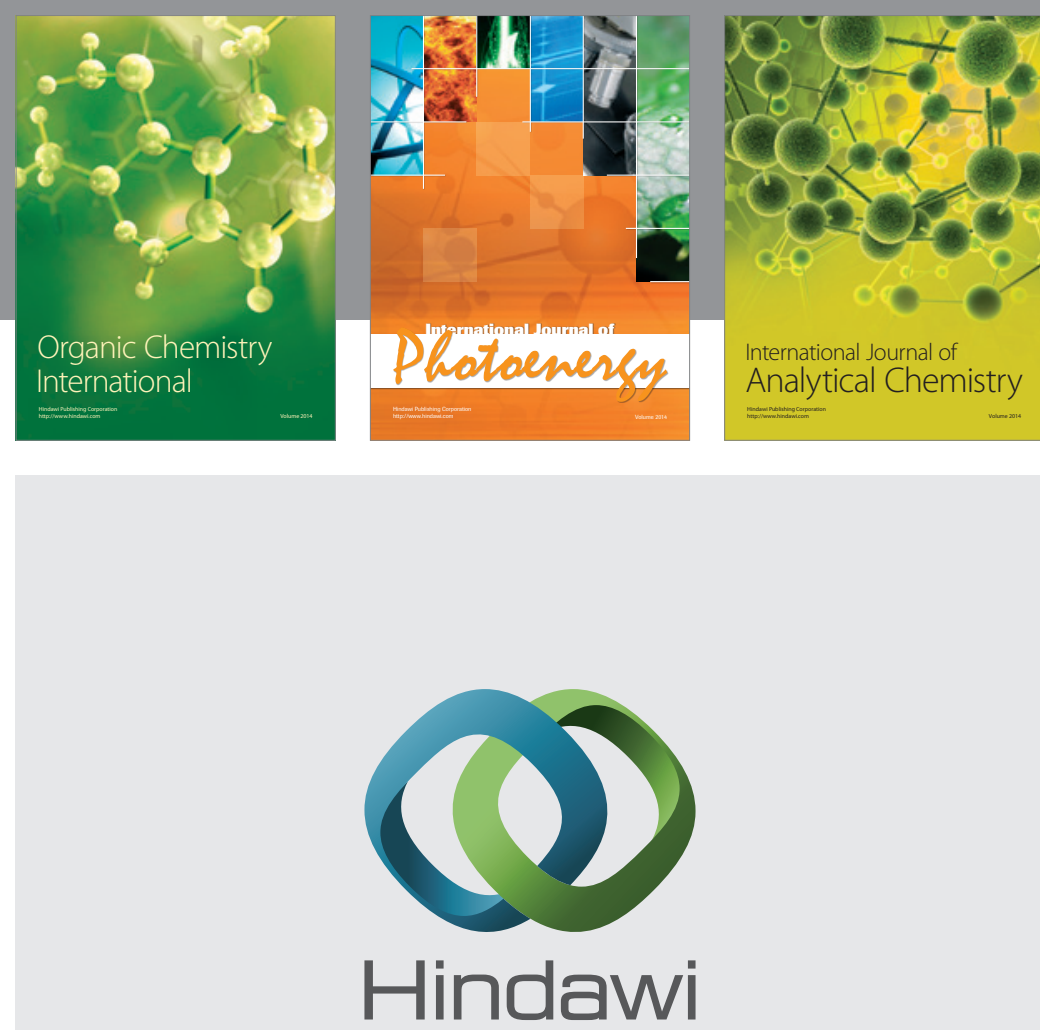

Submit your manuscripts at

http://www.hindawi.com
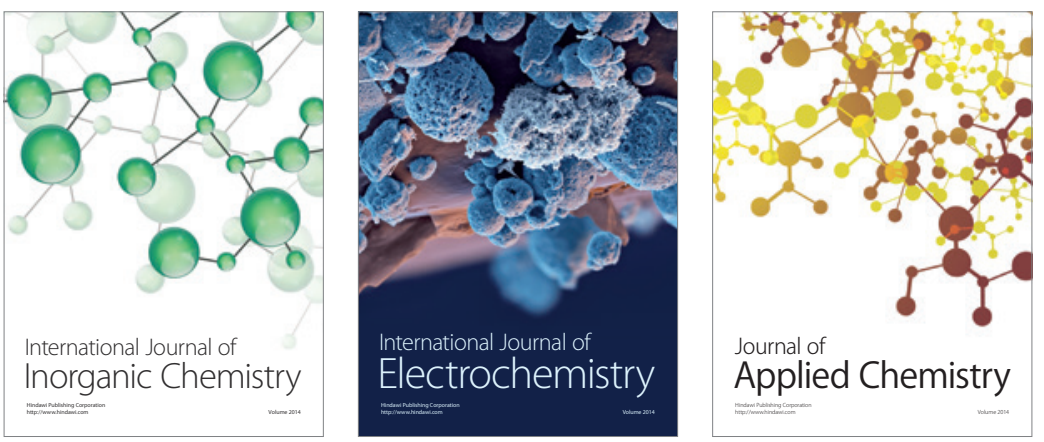

Journal of

Applied Chemistry
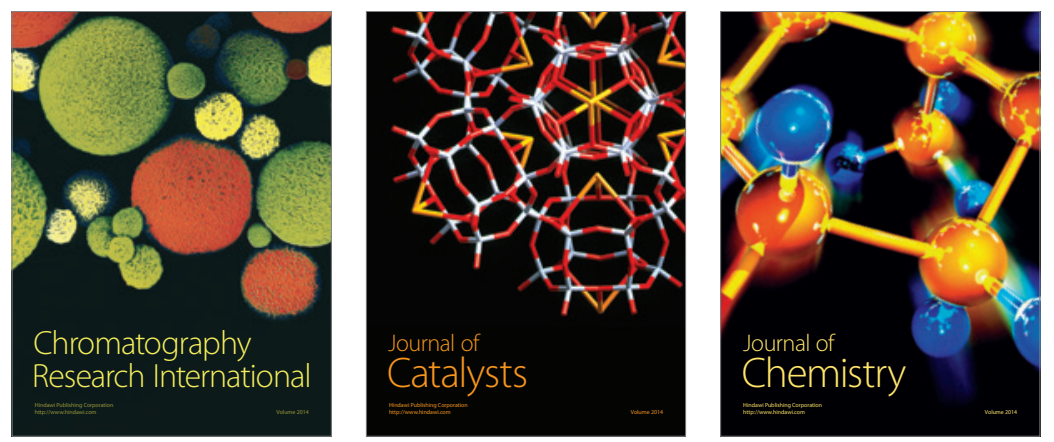
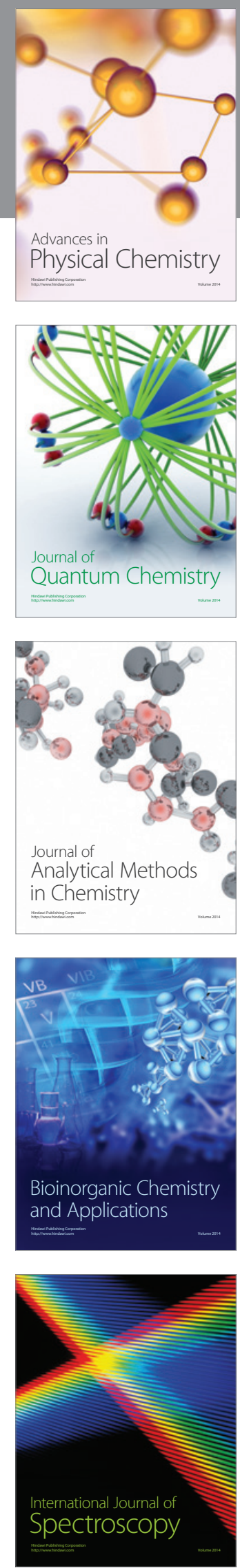